\title{
Research on the Allocation Method of Regional Science and Technology Resources from the Perspective of Rationality
}

\author{
Huozhong Zhang ${ }^{1}$ and Yongjun Zhou $\mathbb{D}^{2}$ \\ ${ }^{1}$ Minnan Science and Technology University, Business College, Quanzhou, Fuzhou 360000, China \\ ${ }^{2}$ Fujian Normal University, Organization Department, Fuzhou, Fujian 350000, China \\ Correspondence should be addressed to Yongjun Zhou; zyj@mku.edu.cn
}

Received 8 November 2021; Revised 29 November 2021; Accepted 14 December 2021; Published 7 January 2022

Academic Editor: Baiyuan Ding

Copyright (c) 2022 Huozhong Zhang and Yongjun Zhou. This is an open access article distributed under the Creative Commons Attribution License, which permits unrestricted use, distribution, and reproduction in any medium, provided the original work is properly cited.

\begin{abstract}
At present, the allocation efficiency of regional scientific and technological resources is low, and there are few research studies on social equity and economic efficiency. Therefore, this paper puts forward the allocation method of regional scientific and technological resources based on rationality. With the support of rationality perspective, the evaluation model of reform path of regional scientific and technological resource allocation is constructed to analyze the economic benefits and equity benefits of regional scientific and technological resource allocation. According to the principle of optimum allocation of regional science and technology resources, threedimensional structure is constructed to maximize national investment and benefit and determine the optimal Pareto of resource allocation to measure the efficiency of resource allocation. The evaluation index system of the reform path of resource allocation is constructed by selecting the evaluation index of the reform path of resource allocation. The benchmark platform of big data was selected to generate data sets to be processed, and the spark on yam platform was used to submit jobs and generate spark job running data sets. The operation performance prediction model was established to optimize the configuration parameters of regional science and technology resources. The analysis results show that the designed method has high configuration capability and good effectiveness.
\end{abstract}

\section{Introduction}

Science and technology are the primary productive forces, and scientific and technological resources are the material basis of scientific and technological creative labor. As the primary resource, the allocation of scientific and technological resources has attracted more and more attention $[1,2]$. Therefore, it is necessary to comprehensively evaluate the allocation efficiency of this specific productivity factor and its regional differences [3]. Countries all over the world have established their own STR sharing platform, which can match various STR services and needs in a lower cost and more convenient way and create the interaction between supply and demand [2]. These sharing platforms make it possible to realize the sharing economy in the field of scientific and technological innovation. The efficiency of scientific and technological input-output is one of the important standards to measure a region's scientific and technological strength. Therefore, using reasonable methods to analyze and study the efficiency of regional scientific and technological resource allocation and putting forward countermeasures and suggestions according to the research results is of great significance to improve regional scientific and technological strength and promote economic development.

In this regard, some scholars have used different methods to quantitatively study the efficiency of scientific and technological resource allocation. Reference [4] puts forward the three-dimensional operation mechanism and system dynamics simulation of regional scientific and technological resource allocation system. A new framework for the operation mechanism of STR distribution system is constructed, and its three submechanisms are designed. The system dynamics model of the operating mechanism is designed and experimentally studied. Simulation results show that the proposed mechanism can effectively improve the sharing rate and value. Finally, some policy suggestions are put forward to help the government improve the management 
mode and optimize the allocation of resources. Reference [5] puts it forward in addition to multilayer online resource allocation and offline planning and configuration in man. The network supporting software defined network and network function virtualization needs to make decisions on two time scales: short-term online resource allocation and medium- and long-term offline planning. In this paper, we first discuss the scale of man supporting software defined network and network function virtualization, with particular attention to the role of delay in capacity planning. A delay-aware multilayer service chain allocation algorithm is proposed to explore a series of maximum delay requirements and their impact on man scale resources. As more data center facilities need to be expanded to approach the edge of the network, reducing the economies of scale of the IT infrastructure, the design cost of low latency requirements will increase. This paper reviews the recent joint calculation of multisite VNF layout and multilayer resource allocation when deploying network services in metropolitan area networks. A set of subroutines included in the multilayer service chain allocation are experimentally verified in the network optimization as a service architecture, which can help the metro network test the open source MANO instance, virtual infrastructure manager, and WAN controller in the mosaic platform.

Most scholars only use a single evaluation method to evaluate the allocation efficiency of regional scientific and technological resources, but there are often differences in the results obtained by using different methods to evaluate the same object. At the same time, each method has its own advantages and disadvantages, and it is impossible to explain which method is good or bad. It is undoubtedly one-sided to use only one method for evaluation. If the first mock exam is the first mock exam, the first mock exam will be able to make use of more information. It can make full use of more information and make full use of the advantages of a single model to make up for the deficiency of single model and make the comprehensive evaluation results more scientific and reasonable. Supported by the rationality perspective, the research method constructs the path evaluation model of regional science and technology resource allocation reform and analyzes the economic and fair benefits of regional science and technology resource allocation. Build a three-dimensional architecture, determine the optimal resource allocation Pareto, and measure the efficiency of resource allocation. Select the evaluation index of resource allocation reform path and build the evaluation index system of resource allocation reform path. Establish spark operation performance prediction model and optimize regional science and technology resource allocation parameters. The results show that the design method has good configuration effect.

\section{Evaluation Index System and the Model of Regional Scientific and Technological Resource Allocation Method Reform Path}

2.1. Constructing the Evaluation Index System of the Reform Path of Regional Science and Technology Resource Allocation. Establishing a reasonable and feasible path evaluation system for regional science and technology resource allocation reform can select an appropriate evaluation index for regional science and technology resource allocation data to reduce the evaluation error of regional science and technology resource allocation reform path $[3,6]$. First, clarify the criteria and basis for the establishment of the system. When designing the evaluation index, according to the principle of system establishment, we can improve the scientificity of the evaluation system of the path of regional scientific and technological resource allocation reform [7]. The construction principle of the path evaluation system of regional science and technology resource allocation reform should not only meet the theoretical design requirements, but also consider the practical experience of regional science and technology resource allocation. Based on the rationality perspective, it is summarized that the following four principles should be followed in the construction of the path evaluation index system of regional science and technology resource allocation reform. They are the principle of combining comparability and operability, the principle of combining systematicness and comprehensiveness, the principle of combining dynamics and foresight, and the principle of combining objectivity and purpose $[8,9]$.

The rationality perspective mainly analyzes the evaluation indicators of regional science and technology resources and selects the appropriate indicators for the evaluation of the path of regional science and technology resource allocation reform $[10,11]$. On the basis of the rational perspective, the assessment can reflect the regional science and technology resources allocation reform path of key contents of fairness, mainly from the human, material, and financial resources and other resources' evaluation index of regional science and technology resources allocation reform path choice; the object of the evaluation index system refers to the planned fixed scientific and technological resource object for which market analysis, technical analysis, and economic analysis are carried out. It is mainly based on the review and reevaluation of the feasibility study conclusion of the planned regional scientific and technological resource project. It is the evaluator's final judgment on the feasibility study from a long-term and objective perspective, forming a path evaluation system for the reform of regional scientific and technological resource allocation from the perspective of rationality, as shown in Table 1.

In Table 1, the data represent the evaluation coefficients. The evaluation coefficient is the data to measure the fluctuation of the reform path of regional science and technology resource allocation from the perspective of human resources, material resources, and financial resources. According to the design requirements of the path evaluation model of regional science and technology resource allocation reform, when constructing the path evaluation index system of regional science and technology resource allocation reform, the appropriate construction principles are adopted to complete the construction of the path evaluation index system of regional science and technology resource allocation reform $[12,13]$. By evaluating the path indicators of scientific and technological resource allocation reform in different regions, the analysis of the path evaluation model of regional scientific and technological resource allocation reform based on the perspective of rationality is realized. 
TABLE 1: Evaluation index system of regional scientific and technological resource allocation reform path.

\begin{tabular}{|c|c|c|c|}
\hline Primary index & Secondary index & Tertiary indicators & $\begin{array}{l}\text { Evaluation } \\
\text { coefficient }\end{array}$ \\
\hline \multirow{7}{*}{$\begin{array}{l}\text { Select evaluation indicators } \\
\text { from the perspective of human } \\
\text { resources }\end{array}$} & Regional science and technology & Proportion of total managers & 0.1360 \\
\hline & resource allocation management & Education of management personnel & 0.1922 \\
\hline & personnel & Administrative level of managers & 0.1751 \\
\hline & & Number of instructors & 0.1140 \\
\hline & Regional science and technology & Instructor structure & 0.1694 \\
\hline & resource allocation instructor & Instructor level & 0.1504 \\
\hline & $\begin{array}{l}\text { Auxiliary personnel for allocation of } \\
\text { regional scientific and technological } \\
\text { resources }\end{array}$ & Proportion of total auxiliary personnel & 0.1922 \\
\hline \multirow{5}{*}{$\begin{array}{l}\text { Select evaluation indicators } \\
\text { from the perspective of } \\
\text { material resources }\end{array}$} & & $\begin{array}{l}\text { Area of various scientific and technological } \\
\text { resources such as government and enterprises }\end{array}$ & 0.1543 \\
\hline & $\begin{array}{l}\text { Area of regional science and } \\
\text { technology resource allocation site }\end{array}$ & $\begin{array}{c}\text { Area of scientific research institutes, intermediary } \\
\text { organizations, and other scientific and } \\
\text { technological resources }\end{array}$ & 0.1359 \\
\hline & \multirow{3}{*}{$\begin{array}{c}\text { Allocation of regional scientific and } \\
\text { technological resources venue } \\
\text { facilities }\end{array}$} & $\begin{array}{l}\text { Quantity of various scientific and technological } \\
\text { resources such as government and enterprises }\end{array}$ & 0.1869 \\
\hline & & Number of special funds for regional science and & 0.1300 \\
\hline & & $\begin{array}{l}\text { technology resource allocation allocated by the } \\
\text { government per capita }\end{array}$ & 0.1542 \\
\hline \multirow{3}{*}{$\begin{array}{l}\text { Select evaluation indicators } \\
\text { from the perspective of } \\
\text { financial resources }\end{array}$} & Government financial allocation & $\begin{array}{l}\text { Number of special funds allocated by the } \\
\text { government to allocate regional science and } \\
\text { technology resources }\end{array}$ & 0.1349 \\
\hline & Social sponsorship and fund raising & $\begin{array}{l}\text { Amount of social sponsorship and fund raising for } \\
\text { allocation of regional scientific and technological } \\
\text { resources per capita }\end{array}$ & 0.1849 \\
\hline & Capital investment & $\begin{array}{c}\text { Number of funds per capita absorbed for } \\
\text { allocation of regional scientific and technological } \\
\text { resources }\end{array}$ & 0.1092 \\
\hline
\end{tabular}

2.2. Constructing the Path Evaluation Model of Regional Science and Technology Resource Allocation Reform. With the in-depth development of regional scientific and technological resource allocation, how to improve the evaluation quality of scientific and technological resource reform path has attracted more and more attention. Select appropriate evaluation indicators to reduce the evaluation error of the path of regional scientific and technological resource allocation reform by evaluating the path indicators of scientific and technological resource allocation reform in different regions [14]. Firstly, collect the information of the regional science and technology resource allocation server, calculate the weight of the server state, and compare it with the internal weight. When the difference value is less than the set threshold, the weight inside the server does not need to be updated; otherwise, the weight inside the server needs to be updated. The new weight is used to allocate regional scientific and technological resources to achieve the best allocation effect. The specific allocation methods are as follows. Based on the analysis of the application principle of rationality, the rationality perspective principle is adopted to decompose the reform path of regional science and technology resource allocation layer by layer, so that the meaning of elements at each level is complementary and cross, the upper and lower elements are parent-child relations, and the lower elements are used as evaluation indicators $[15,16]$. The hierarchical structure of the evaluation of the reform path of regional science and technology resource allocation is shown in Figure 1.
According to the hierarchical structure of the evaluation of the reform path of regional science and technology resource allocation, the combination weight of the bottom elements in the evaluation index system is calculated, and the weight of the lower elements of adjacent levels to the upper elements is calculated by the accurate method [17], and then the combination weight of the bottom elements to the reform path of regional science and technology resource allocation is calculated. The calculation formula is

$$
W=\left(w_{1}, w_{2}, w_{3}, \ldots, w_{n}\right)^{T} .
$$

Based on the combination weight of the underlying elements to the reform path of regional science and technology resource allocation, the evaluation coefficient of the reform path of regional science and technology resource allocation is calculated as follows:

$$
n_{J}^{(A)}=\sum_{i=1}^{k} b_{i}^{(A)}
$$

Here, $A$ represents the evaluation index, $J$ represents the evaluated person, and $b_{i}^{(A)}$ represents the evaluation coefficient of the path of regional scientific and technological resource allocation reform. For the evaluation index $A$ of the reform path of regional science and technology resource allocation, the total evaluation coefficient $C_{\mathrm{JK}}^{(A)}$ of the evaluated person belonging to each category of rationality perspective is 


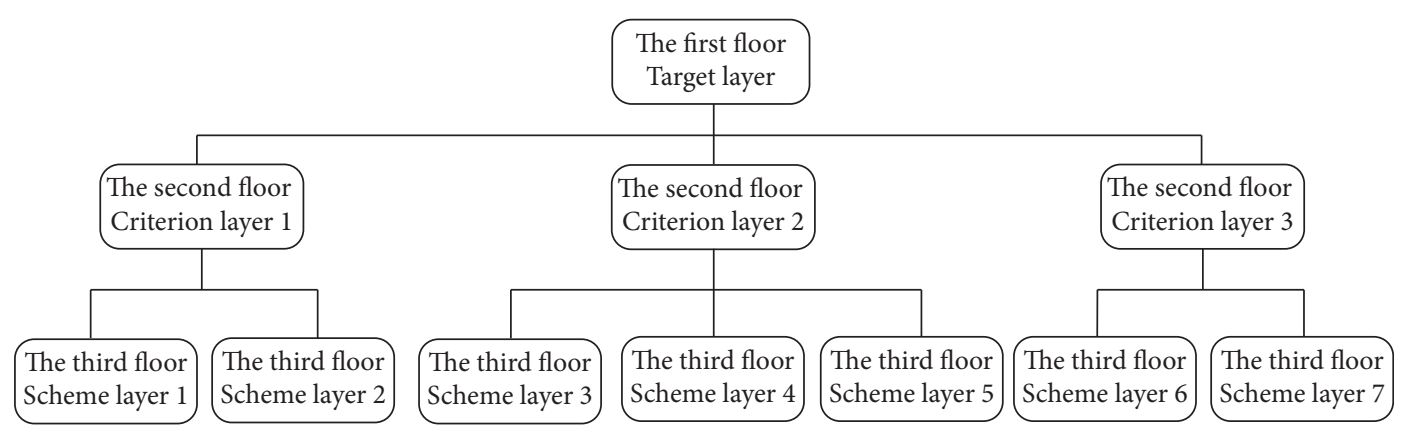

FIGURE 1: Hierarchical structure of path evaluation of regional science and technology resource allocation reform.

$$
C_{\mathrm{JK}}^{(A)}=\sum_{I=1}^{i} f_{K}\left(d_{\mathrm{JI}}\right) .
$$

Here, $C_{\mathrm{JK}}^{(A)}$ represents the total evaluation coefficient, $d_{\mathrm{JI}}$ represents the weight of each evaluation index, and $f_{K}$ represents the weight of a single index.

According to the total evaluation coefficient, the evaluation path weight vector and weight matrix of regional scientific and technological resources allocation are calculated [18]. $n_{J}^{(A)}$ and $C_{\mathrm{JK}}^{(A)}$ can directly calculate the evaluation weight $r_{\mathrm{JK}}^{(A)}$ and weight vector $r_{J}^{(A)}$ of the j-th evaluator in the evaluation index $A$ belonging to the $k$-th rationality perspective:

$$
r_{\mathrm{JK}}^{(A)}=\frac{C_{\mathrm{JK}}^{(A)}}{n_{J}^{(A)}} .
$$

Here, $K=1,2,3, \ldots, k$; then the weight line vector $r_{\mathrm{jk}}^{(A)}$ of rationality perspective evaluation can be obtained:

$$
r_{\mathrm{jK}}^{(A)}=\left[r_{j 1}^{(A)}, r_{j 2}^{(A)}, r_{j 1}^{(A)}, \ldots, r_{\mathrm{jk}}^{(A)}\right] \text {. }
$$

Considering $J=1,2,3, \ldots, j$, the weight column vector $r_{\mathrm{JK}}^{(A)}$ of rationality perspective evaluation can be obtained:

$$
r_{\mathrm{JK}}^{(A)}=\left[r_{1 k}^{(A)}, r_{2 k}^{(A)}, r_{3 k}^{(A)}, \ldots, r_{\mathrm{jk}}^{(A)}\right]^{T}
$$

Thus, the Atlas evaluation weight matrix $R^{(A)}=\left[r_{\mathrm{JK}}^{(A)}\right]$ of the evaluators for the evaluation index $A$ of the path of regional scientific and technological resource allocation reform can be obtained:

$$
R^{(A)}=\left[\begin{array}{ccccc}
r_{11}^{(A)} & r_{12}^{(A)} & r_{13}^{(A)} & \cdots & r_{1 k}^{(A)} \\
r_{21}^{(A)} & r_{22}^{(A)} & r_{23}^{(A)} & \cdots & r_{2 k}^{(A)} \\
\cdots & & & & \\
r_{j 1}^{(A)} & r_{j 2}^{(A)} & r_{j 3}^{(A)} & \cdots & r_{j \mathrm{k}}^{(A)}
\end{array}\right] .
$$

Use the Atlas evaluation weight matrix to complete the evaluation of the evaluation index of the path of regional scientific and technological resource allocation reform, which is obtained by $R^{(A)}$ :

$$
r_{J}^{*(A)}=\max _{K}\left\{r_{\mathrm{JK}}^{(A)}\right\} .
$$

Thus, the evaluation weight vector of the path of regional scientific and technological resource allocation reform can be obtained:

$$
r^{*(A)}=\left\{r_{1}^{*(A)}, r_{2}^{*(A)}, r_{3}^{*(A)}, \ldots, r_{j}^{*(A)}\right\}
$$

Here, $r^{*(A)}$ represents the evaluation vector. By synthesizing all evaluation factors, determining the Atlas category of the evaluator, and automatically arranging $r^{*}(A)$ into a matrix, the comprehensive evaluation vector of the evaluator can be obtained:

$$
r_{J}=\sum_{K=1}^{k} B_{K} \times R_{\mathrm{JK}} .
$$

Here, $B_{K}$ represents the weight coefficient of different maps, and the specific value can be determined before evaluation; $R_{\mathrm{JK}}$ refers to the total evaluation right of the evaluated person rated as different map categories.

Based on the above calculation, the periodicity of the regional science and technology resource allocation server node is based on the collection of regional science and technology resources. According to the calculated weight of the resource allocation load, it is transmitted to the scheduler. The specific derivation process is shown in Figure 2.

According to the above process, in order to meet the evaluation model of regional science and technology resources allocation reform path design requirements, on the basis of the rational perspective, we summed up the evaluation index system of regional science and technology resource allocation reform path construction principles, and from the aspects of human, material, and financial resources, the evaluation index of regional science and technology resources allocation reform path to choose completed the construction of the evaluation index system of the reform path of regional science and technology resource allocation. According to the hierarchical structure of the evaluation of regional science and technology resources allocation reform path, the computing system of regional science and technology resource allocation reform path evaluation coefficient, using the weight vector and weight matrix, evaluation of the different areas of science and technology resource allocation reform path index, completed the evaluation model of regional science and technology resources allocation reform path construction, realizing the evaluation of 


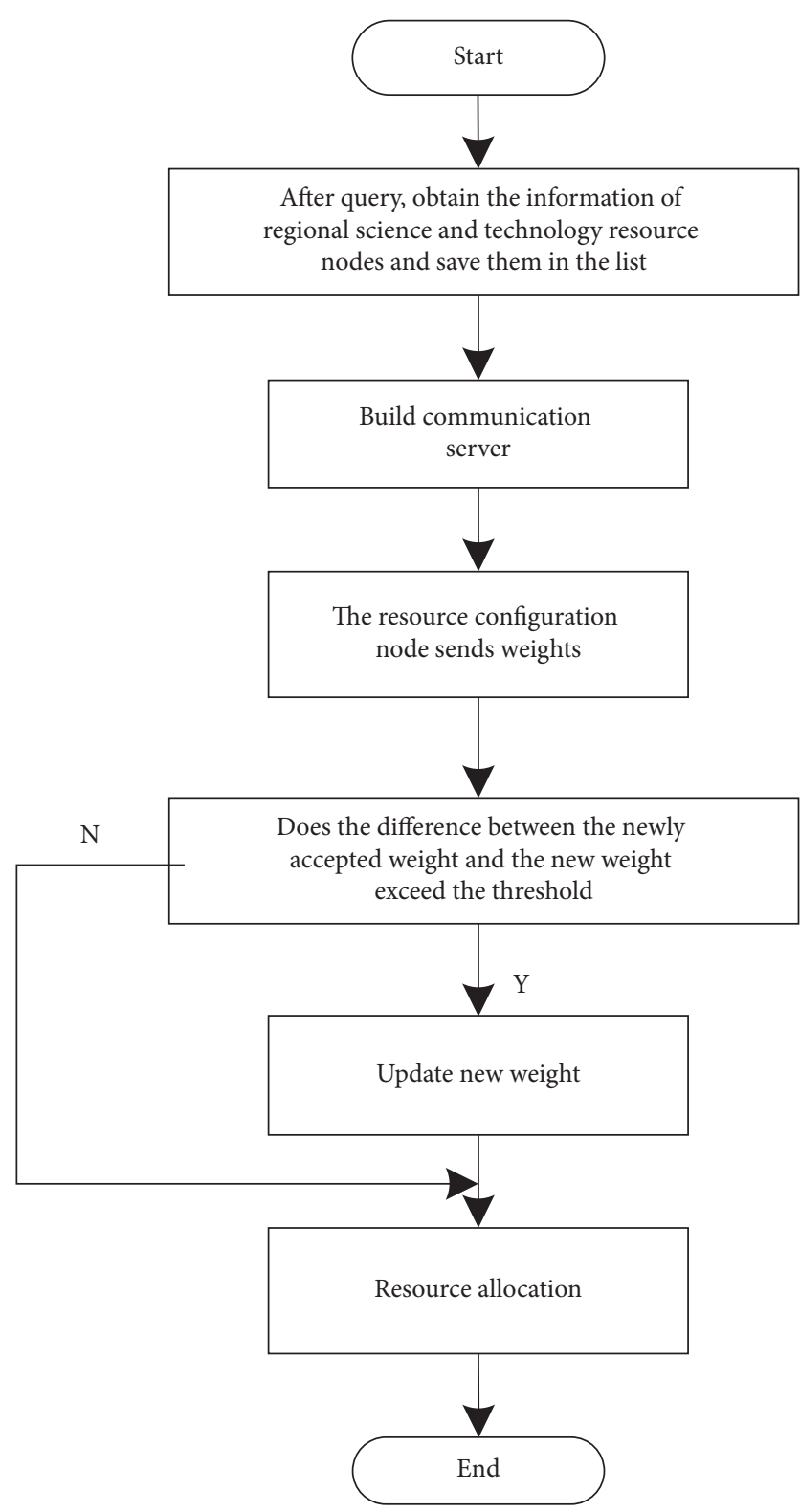

FIGURE 2: Construction flowchart of the path evaluation model for regional science and technology resource allocation reform.

regional science and technology resources allocation reform path analysis.

\section{Spark Operation Performance Prediction Model for Regional Science and Technology Resource Allocation under the Market Economy System}

Under the mechanism of market economy, individuals and social organizations are the main trading media, which plays a key role in the allocation of regional scientific and technological resources [19-21]. On the basis of perfecting the basic competitive links, the mechanism studies the specific system and plays a regulatory role in the allocation of regional scientific and technological resources.
For the research on the allocation efficiency of regional scientific and technological resources, build a market economic system framework, as shown in Figure 3.

Give full play to the positive role of economic analysis in optimizing the allocation of regional scientific and technological resources, study its characteristics and relevant mechanisms, ensure the fair distribution of regional scientific and technological resources, take into account economic interests, and achieve rational allocation.

3.1. Analysis of Economic Benefits. The allocation of regional scientific and technological resources requires a certain cost, which is prone to economic problems [22]. At the economic level, the allocation of regional scientific and technological resources should follow the principle of maximizing benefits at the lowest cost. Combined with local reality, whether the allocation of scientific and technological resources reaches the best state, comprehensively evaluate the allocation efficiency of regional scientific and technological resources and increase resources on the premise of ensuring that it does not harm the economic interests of others $[23,24]$.

3.2. Analysis of Equity Benefit. One of the important issues in analyzing the allocation of regional science and technology resources of local governments from an economic point of view is fairness. Under the market economy system, under the conditions of equality and harmony, the distribution of regional scientific and technological resources also needs to be fair $[25,26]$. In view of the large gap between urban and rural areas, local governments should actively formulate relevant policies, give full play to the role of government mechanisms, standardize the market environment, and stop the vicious price rise in the allocation of regional scientific and technological resources.

3.3. Research on the Allocation Efficiency of Regional Science and Technology Resources of Local Government. With the support of market economy mechanism, analyze the problems of economic benefits and fair benefits, and determine the optimal Pareto of regional scientific and technological resource allocation on the premise of ensuring that it does not harm the economic interests of others, so as to realize the rational allocation of regional scientific and technological resources by local governments.

3.3.1. Building a Three-Dimensional Architecture. Under the market economy system, the allocation efficiency of regional science and technology resources of local governments is studied in a three-dimensional structure. The local government that allocates regional scientific and technological resources is the subject of responsibility and management [27]. According to the principle of optimal allocation of resources, local resources are allocated in order to maximize national investment and benefits. It breaks the current practice of setting according to administrative divisions, greatly reduces the number, improves the construction 


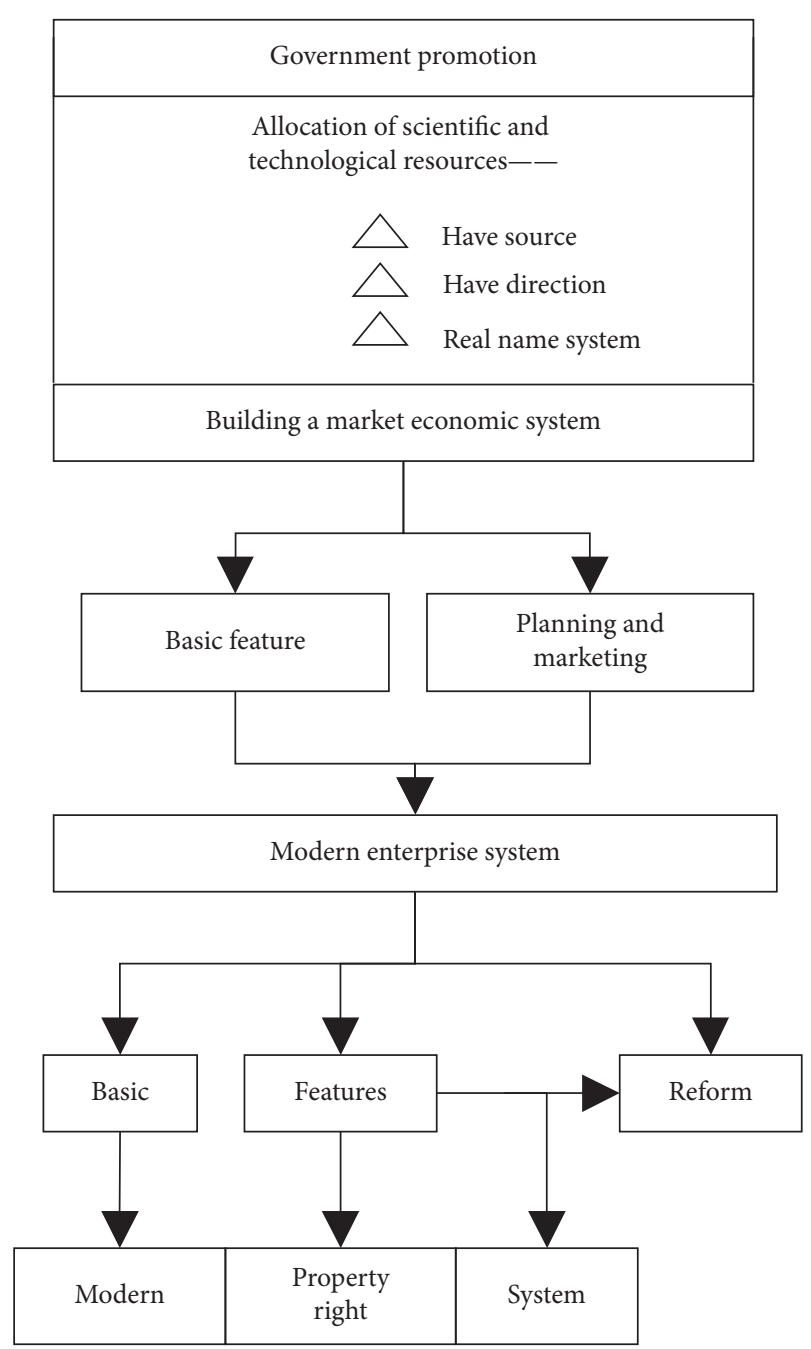

FIGURE 3: Institutional framework of market economy.

standards, and leaves a certain space for the development of local governments [28, 29]. Developing and applying advanced means representing the industry level and stabilizing market prices are the main functions of local governments in allocating regional scientific and technological resources [30]. The local government will also return this part of the tax to the insurance fund. The insurance institution can be a commercial operation. While ensuring its own development, on the one hand, it accepts social individuals to pay insurance premiums, mainly the quota fund of the local government, which is used to allocate local regional science and technology resources.

3.3.2. Pareto Optimality. On the premise of investing in the market economic system, the allocation of regional science and technology resources of local governments reaches Pareto optimal. Because of the particularity of regional science and technology resources, we can choose the projects and plans that can achieve specific goals and have the lowest cost and change the cost-benefit analysis method to the costeffectiveness analysis method to measure the efficiency of resource allocation.
It is assumed that the two allocation modes of regional scientific and technological resources are $\mathrm{X}$ and $\mathrm{Y}$, and the given quantities are X1 and Y1. National science and technology parks and local science and technology parks are $\mathrm{A}$ and B, respectively. Figure 4 shows the resource distribution between the two science parks.

The horizontal length of the block diagram represents the number X1 of the first type of regional science and technology resource allocation $\mathrm{X}$, and the vertical height represents the number $\mathrm{Y} 1$ of regional science and technology resource allocation $\mathrm{Y}$. OA is the origin of national science park $A$, and local science park $B$ is the origin of $O B$. The consumption of $\mathrm{X}$ in the figure from left to right represents the regional science and technology resource allocation $\mathrm{X}$ of national science and technology park $A$, while the vertical figure represents the science and technology resource allocation Y of public medical institution A. From the OB level to the left, it represents the consumption of private science and technology parks in regional science and technology resource allocation $\mathrm{X}$ and $\mathrm{XB}$, and from the vertical direction it represents the consumption of private science and technology park B in allocation Y and YB. For any point, such as point $\mathrm{A}$, it is equivalent to the cost of national science park $\mathrm{A}$ and local science park B [31]. Therefore, the following formula holds:

$$
\begin{aligned}
& \mathrm{XA}+\mathrm{XB}=1, \\
& \mathrm{YA}+\mathrm{YB}=1 .
\end{aligned}
$$

Determine a group of quantities at any point in the block diagram, which represents the consumption of each scientific and technological resource allocated by national and local science and technology parks and conforms to the above formula.

When the transaction reaches a certain state, any regional science and technology resource allocation transaction will reduce the satisfaction of at least one person, so this state is the best state of the transaction $[32,33]$. In terms of economic benefits, the allocation efficiency of scientific and technological resources in this region is the highest.

In view of a series of problems in the development of the research method of allocation efficiency supported by theory, this paper studies the efficiency of the government's allocation of regional scientific and technological resources under the local market economy system from the perspectives of social equity and economic efficiency and briefly analyzes the government mechanism and the role of market regulation.

\subsection{Spark Job Performance Prediction Model}

3.4.1. Spark Job Performance. Spark operation performance formula is as follows:

$$
\text { perf }=F(p, d, r, c) .
$$

In formula (12), perf and $p$ represent the job operation performance and the job itself, respectively, and the spark job operation time is used to reflect the job operation 


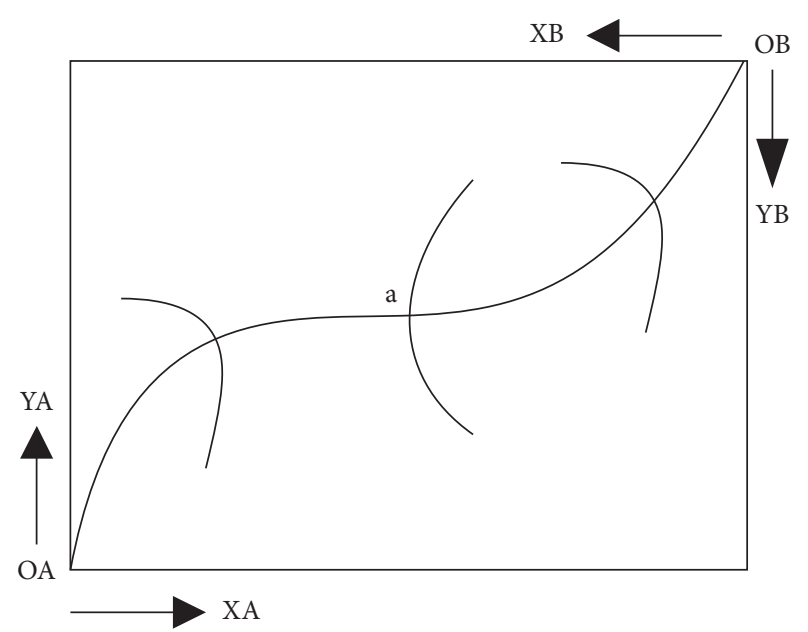

Figure 4: Distribution of regional science and technology resources between the two science and technology parks.

performance; $d$ and $r$, respectively, represent the data scale to be processed by the job and the available hardware resources of the cluster; $c$ indicates the configuration parameters of regional science and technology resources when submitting the operation. This paper studies the impact of regional science and technology resource allocation parameter $c$ and data scale $d$ of job $p$ on job performance when hardware resource $r$ is sufficient.

3.4.2. Job Acquisition and Preprocessing. Select the big data benchmark platform to generate the data set to be processed and implement sampling in the regional science and technology resource allocation parameter space; the spark on yam platform is used to submit jobs. The spark on yam platform is based on the management mechanism of yarn for the whole big data benchmark platform, analyzes the relationship between the resource manager yarn and the computing engine spark, and studies how to monitor the spark task in the big data platform by monitoring yarn, so as to ensure the availability of the whole spark on yam platform. This generates the spark job run dataset.

The structure diagram of spark platform acquisition operation and preprocessing operation is shown in Figure 5.

There are great differences in the value range of science and technology resource allocation parameters in each region of spark platform. Before establishing the operation performance prediction model, the values of science and technology resource allocation parameters in each region need to be normalized. The formula of normalized values is as follows:

$$
C_{j}=\frac{C_{j, \text { ori }}-C_{j, \min }}{C_{j, \max }-C_{j, \min }} .
$$

In formula (13), $C_{j, \text { ori }}$ and $C_{j \text {, max }}$, respectively, represent the original value of regional science and technology resource allocation parameters and the maximum value of all values; $C_{j \text {, min }}$ refers to the minimum value of all science and technology resource allocation parameters in the region. All

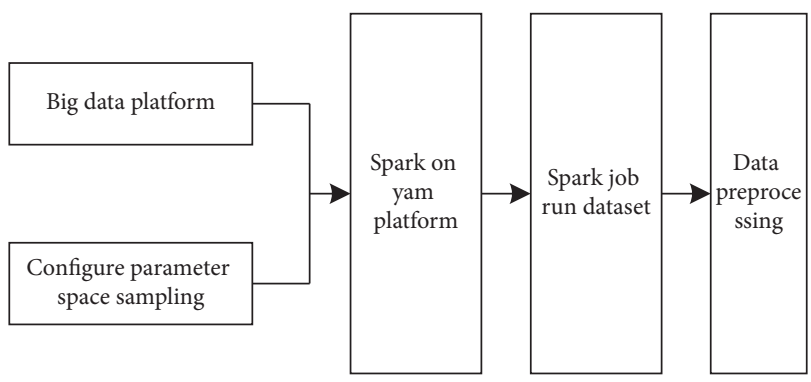

FIGURE 5: Spark job acquisition and preprocessing.

values are converted to the same data range through the normalization of regional science and technology resource allocation parameters [34]. The data in the same order of magnitude range can effectively improve the comparability of difference characteristic data.

3.4.3. Establishment of Job Performance Prediction Model. The support vector machine algorithm is selected to establish the spark operation performance prediction model. The vector formed by the spark operation data scale and regional science and technology resource allocation parameters is taken as the independent variable, the spark operation time vector is taken as the dependent variable, and the radial basis function $K\left(x_{i}, x\right)$ is selected as the kernel function trained by the support vector regression algorithm. The formula is as follows:

$$
K\left(x_{i}, x\right)=\exp \left(-\frac{\left\|x_{i}-x\right\|^{2}}{2 \sigma^{2}}\right) .
$$

By mapping data from low dimensional space to high dimensional space through formula (14), nonlinear data can be effectively processed.

It is necessary to normalize and preprocess the original data set, divide the preprocessed original data set, divide the data in the original data set into training set and test set in the proportion of $8: 2$, use the empirical cross validation method to not repeatedly sample the training set to avoid overfitting of the model, divide the training set into subsets of the same scale, and select one of them as the validation set in order. The remaining sets are used as training sets, and the minimum cross validation error support vector machine model is used as the final prediction model.

$A=\left\{a_{1}, a_{2}, \ldots, a_{n}\right\}$ is used to represent the data set. The number of observed values in the data set is $n$. The predicted values of the corresponding model of each observed value are expressed by $b_{1}, b_{2} \cdots$ and $b_{n}$, respectively. The average observed value formula is as follows:

$$
\bar{a}=\frac{1}{n} \sum_{i=1}^{n} b_{i} .
$$

The evaluation indexes applied to spark operation performance prediction model are as follows:

(1) Goodness of fit

The fitting degree of spark operation performance prediction model is better when the goodness of fit 
value is closer to 1 . The goodness of fit formula is as follows:

$$
R^{2}=1-\frac{\sum_{i=1}^{n}\left(b_{i}-a_{i}\right)^{2}}{\sum_{i=1}^{n}\left(b_{i}-\bar{a}\right)^{2}} .
$$

(2) Root mean square error

The higher the prediction accuracy of the job performance prediction model, the smaller the root mean square error. The root mean square error result is the square sum of the mean value of the prediction error, and then the square is processed, and its formula is as follows:

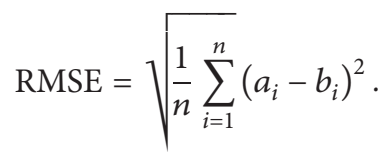

\section{(3) Average absolute percentage error}

The average absolute percentage error is the average value of absolute error, and its formula is as follows:

$$
\text { MAPE }=\frac{1}{n} \sum_{i=1}^{n} \frac{\left|a_{i}-b_{i}\right|}{a_{i}}
$$

3.5. Parameter Optimization Algorithm of Regional Science and Technology Resource Allocation. Taking the minimization of operation cost as the optimization goal of resource regional science and technology resource allocation for activity performance prediction, taking full account of the two dimensions of cluster resource utilization and activity running time, the optimization goal is to minimize cluster consumption cost.

Define job execution cost and optimize resource utilization and job execution time. The optimization objective formula is as follows:

$$
O=\min \left(\mathrm{ET} *\left(\frac{\text { used Mem }}{\text { total Mem }}+\frac{\text { used } \mathrm{CPU}}{\text { total CPU }}\right)\right) .
$$

In formula (19), ET and used Mem, respectively, represent the execution time of spark job and the cluster memory occupied by the job; total Mem and used CPU, respectively, represent the total memory of the cluster and the CPU occupied by jobs, and total CPU represents the total CPU of the cluster.

Based on the relationship between the allocation parameters of scientific and technological resources in the operation area and the operation execution time, the optimization objective formula is as follows:

$O=\min \left(F(p, d, r, c) *\left(\frac{\text { used Mem }}{\text { total Mem }}+\frac{\text { used CPU }}{\text { total CPU }}\right)\right)$.

The input data scale and resource utilization characteristics of spark operation are known. The optimization problem of science and technology resource allocation in resource area can be transformed into the combination of parameters of science and technology resource allocation in all regions, which belongs to the solution space problem of the least cost optimization search.

Aiming at the problem of market failure, this paper completes the research on the allocation method of regional science and technology resources from the perspective of rationality.

\section{Experimental Analysis}

In order to better verify the effect and feasibility of the regional science and technology resource allocation method designed from the perspective of rationality and explore whether it can be applied to the actual resource allocation in the future, design experiments. In order to make full use of the data advantages of the regional science and technology resource allocation system, cooperate with the regional science and technology resource allocation reform path evaluation work and synchronize the regional science and technology resource allocation reform path evaluation information to the rationality perspective; the appraisers shall be notified regularly of the evaluation information with simple evaluation data structure, so as to facilitate the appraisers to successfully complete the evaluation. Due to the complex business logic of the evaluation of the path of regional science and technology resource allocation reform, a large amount of background data needs to be called during the experiment. In terms of evaluation data processing, a reasonable perspective is adopted to alleviate the pressure of a large amount of data. Firstly, a large number of data in the regional science and technology resource allocation database are extracted from the data set, then the relevant data are processed through the model for evaluation and analysis, and finally the analysis results are displayed. The specific functions between each level constitute the integrity of the evaluation of the path of regional scientific and technological resource allocation reform and ensure the smooth progress of the evaluation work.

In terms of data collection, the evaluation data required by the path evaluation of regional science and technology resource allocation reform can be obtained through the regional science and technology resource allocation system. The regional science and technology resource allocation system processes the evaluation data provided by the evaluation report declared by the regional science and technology resource allocation personnel through the data warehouse technology, provides the basic data source for the evaluation of the path of regional science and technology resource allocation reform, and is also the basic guarantee for the smooth development of the path evaluation of regional science and technology resource allocation reform.

Suppose Spark + Hadoop is set as the spark cluster environment, which contains three nodes, one master node and two slave nodes. The storage system is HDFS, the resource manager is yarn, and the resource manager yarn version is 2.6.5. Use Cent OS linux release 7.6.1810 as the node resource to configure the operating system. According to the resources occupied during the operation of jobs, Word Count, Sort, K-means, and Naive Bayes jobs are selected as 


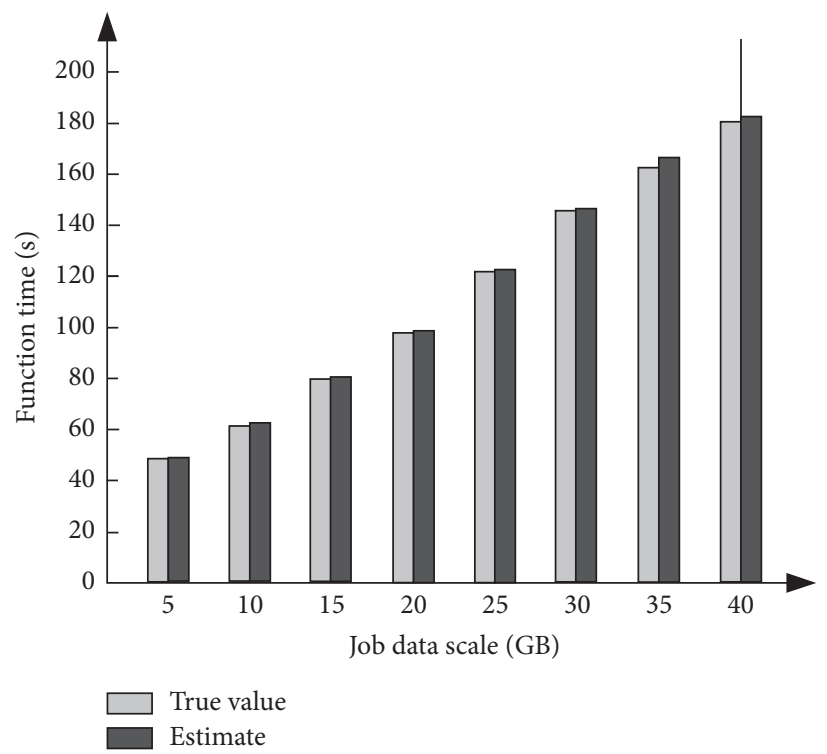

Figure 6: Comparison between predicted execution time and actual execution time.

experimental objects to test the optimization of resource allocation when the above jobs are completed by this method, and the studies in [4] and [5] are selected as comparison methods. The grid resource scheduler in GridSim simulation platform is extended by EFRB, and 100 tasks are constructed to form a resource scheduling set. The execution time of each resource scheduling task is $120 \mathrm{~s}$, and the total task is divided into 10 queues. Science and technology resources are divided into several regions, with an average of two LANs in each region. The storage capacity of the primary site is $300 \mathrm{~GB}$, and the number of nodes varies from 200 to 2000, with an increase of 200. To ensure network connectivity, $\delta$ is set to $\delta=0.65$.

After clarifying the source of experimental data, the following experimental steps are formulated:

Step 1: organize and preprocess the experimental data. Step 2: randomly generate the evaluation data format by using the evaluation model of the reform path of regional science and technology resource allocation based on the rationality perspective.

Step 3: process the generated evaluation data.

Step 4: calculate the path evaluation coefficient and comprehensive evaluation vector of regional scientific and technological resource allocation reform.

Step 5: take the complexity of regional science and technology resource allocation data as the independent variable, and analyze and count the evaluation error value.

The comparison results between the predicted sort job execution time and the actual execution time are shown in Figure 6.

As can be seen from the experimental results in Figure 6, there is a small error between the predicted job running time by this method and the actual job running time. The overall trend shows that the actual job running time is very consistent with the job running time predicted by this method, which verifies that the job performance prediction model adopted by this method has high prediction effectiveness.

Table 2 shows the prediction performance of regional science and technology resource allocation under different training set sizes by using the three methods.

According to the experimental results in Table 2, using this method to predict the operation time of regional science and technology resource allocation has higher prediction accuracy. The three indicators of the operation time predicted by this method are the best, which effectively verifies that this method has excellent prediction performance. With the increase of the scale of training data set, the root mean square error and average percentage error of the job prediction model used in this method are reduced, which verifies that the job prediction model used in this method has high fitting effect. This method has high stability and can be applied to the actual job running scenario.

Three methods are used to run different jobs 100 times, respectively, compare the quality of the optimal solution obtained by optimizing the configuration parameters by different methods, and select the average value of convergence results as the evaluation index of the effectiveness of configuration parameter optimization.

The smaller the average value of the convergence results, the better the convergence effect of the representation method. The average value of convergence results of optimized configuration parameters by different methods is counted, and the statistical results are shown in Figure 7.

In Figure 7, experimental results show that the proposed method has better convergence effect and stability. This method has high stability for different jobs, and the standard deviation of the convergence result is very close to 0 , which validates the high quality and strong adaptability of this algorithm. 
TABLE 2: Comparison of prediction performance of regional science and technology resource allocation.

\begin{tabular}{|c|c|c|c|c|c|c|c|c|c|}
\hline \multirow[b]{2}{*}{$\begin{array}{l}\text { Training } \\
\text { set size }(\%)\end{array}$} & \multicolumn{3}{|c|}{ Paper method } & \multicolumn{3}{|c|}{ Reference [4] method } & \multicolumn{3}{|c|}{ Reference [5] method } \\
\hline & $\begin{array}{c}\text { Goodness } \\
\text { of fit }\end{array}$ & $\begin{array}{l}\text { Root } \\
\text { mean } \\
\text { square } \\
\text { error }\end{array}$ & $\begin{array}{l}\text { Average } \\
\text { percentage } \\
\text { error }\end{array}$ & $\begin{array}{c}\text { Goodness } \\
\text { of fit }\end{array}$ & $\begin{array}{l}\text { Root } \\
\text { mean } \\
\text { square } \\
\text { error }\end{array}$ & $\begin{array}{c}\text { Average } \\
\text { percentage } \\
\text { error }\end{array}$ & $\begin{array}{c}\text { Goodness } \\
\text { of fit }\end{array}$ & $\begin{array}{l}\text { Root } \\
\text { mean } \\
\text { square } \\
\text { error }\end{array}$ & $\begin{array}{c}\text { Average } \\
\text { percentage } \\
\text { error }\end{array}$ \\
\hline 10 & 0.81 & 31.52 & 3.52 & 0.69 & 65.25 & 9.52 & 0.68 & 67.52 & 10.52 \\
\hline 20 & 0.82 & 31.25 & 3.42 & 0.71 & 64.25 & 9.43 & 0.69 & 67.15 & 9.52 \\
\hline 30 & 0.83 & 30.95 & 3.28 & 0.72 & 63.52 & 9.05 & 0.71 & 66.85 & 9.05 \\
\hline 40 & 0.83 & 30.85 & 3.12 & 0.73 & 62.43 & 8.94 & 0.73 & 66.24 & 8.76 \\
\hline 50 & 0.84 & 30.52 & 3.05 & 0.74 & 61.52 & 8.61 & 0.74 & 65.42 & 8.52 \\
\hline 60 & 0.86 & 30.25 & 2.95 & 0.75 & 60.85 & 7.52 & 0.75 & 65.02 & 8.13 \\
\hline 70 & 0.87 & 29.52 & 2.85 & 0.77 & 60.25 & 7.13 & 0.76 & 64.23 & 7.85 \\
\hline 80 & 0.88 & 29.34 & 2.76 & 0.78 & 59.45 & 7.25 & 0.77 & 64.02 & 7.46 \\
\hline 90 & 0.89 & 29.14 & 2.67 & 0.79 & 59.05 & 7.05 & 0.78 & 63.52 & 7.25 \\
\hline
\end{tabular}

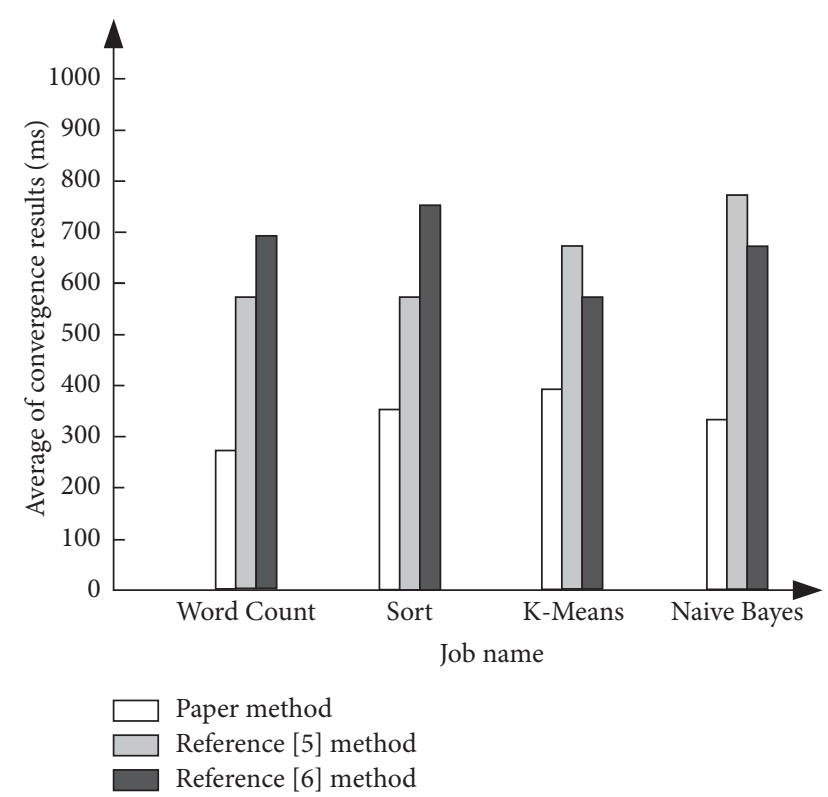

Figure 7: Comparison of the average convergence results of different methods.

In conclusion, there is a small error between the predicted operation time and the actual operation time of the regional science and technology resource allocation method based on the rationality perspective, which has high prediction effectiveness. Using this method to predict the operation time has higher prediction accuracy and fitting effect. At the same time, the convergence effect and stability are good, which can be applied to the actual operation scenario.

\section{Conclusion}

Today, with the integration of science and technology, economy, and social development, it has become a common strategic choice for all countries in the world to continuously increase investment in science and technology resources. At present, government departments at all levels are constantly increasing the investment in related funds of regional scientific and technological resources, gradually accelerating the growth rate of scientific and technological resources, and paying attention to their impact on economic and social development and supporting ability. While making efforts to increase input, we must attach great importance to the utilization efficiency of scientific and technological resources. If we just blindly increase scientific and technological input without paying attention to the rational allocation of scientific and technological resources, it is bound to cause a huge waste of scientific and technological resources. Experiments show that this method is effective to optimize the allocation of regional science and technology resources.

\section{Data Availability}

The raw data supporting the conclusions of this article will be made available by the authors, without undue reservation.

\section{Conflicts of Interest}

The authors declare that they have no conflicts of interest regarding this work.

\section{Acknowledgments}

This work was supported by Educational and Scientific Research Projects for Young and Middle-Aged Teachers of the Education Department of Fujian Province, Research on the Promotion Strategies of Scientific and Technological Innovation Policies of Private Enterprises in Quanzhou (JAS21449) and Policy Decision and Consultation Projects of Quanzhou Association for Science and Technology, Research on the Innovation of Allocation Mechanism of Scientific and Technological Resources in Quanzhou City in Response to the 14th Five-Year Plan (Quanzhou Association for Science and Technology [2020] no. 45).

\section{References}

[1] G. Sun, H. Chen, and Y. Mao, "The efficiency analysis model of technological innovation resource allocation of coastal Enterprises based on genetic algorithm," Journal of Coastal Research, vol. 103, no. 1, p. 691, 2020.

[2] J. Wang and L. Yang, "Does factor endowment allocation improve technological innovation performance? An empirical 
study on the Yangtze River Delta region," The Science of the Total Environment, vol. 716, no. 5, Article ID 137107, 2020.

[3] W. Zhen, Z. X. Gang, and Z. Ying, "Biased technological progress and total factor productivity growth: from the perspective of China's renewable energy industry," Renewable and Sustainable Energy Reviews, vol. 146, no. 1, pp. 1-10, 2021.

[4] J. Lu, G. Jia, and W. Liu, "A three-dimensional operating mechanism for regional science and technology resource allocation system and its system dynamics simulation," IEEE Transactions on Engineering Management, no. 99, pp. 1-14, 2020.

[5] M. Garrich, J. L. R. Gazquez, F. J. M. Muro et al., "IT and multi-layer online resource allocation and offline planning in metropolitan networks," Journal of Lightwave Technology, vol. 38, no. 12, pp. 3190-3199, 2020.

[6] I. Park, B. Yoon, S. Kim, and H. Seol, "Technological opportunities discovery for safety through topic modeling and opinion mining in the fourth industrial revolution: the case of artificial intelligence," IEEE Transactions on Engineering Management, vol. 68, no. 5, pp. 1-16, 2019.

[7] A. I. Rudskoi, V. V. Mishin, and I. A. Shishov, "Scientific and technological basis of production of thin beryllium foils with improved operational properties," Doklady Chemistry, vol. 497, no. 2, pp. 55-58, 2021.

[8] Y. Fan, X. Zhao, Z. Han et al., "Scientific and technological progress and future perspectives of the solar assisted heat pump (SAHP) system," Energy, vol. 229, no. 8, Article ID 120719, 2021.

[9] T. C. Pimentel, L. R. Brandão, M. P. D. Oliveira, W. K. A. D. Costa, and M. Magnani, "Health benefits and technological effects of Lacticaseibacillus casei -01: an overview of the scientific literature," Trends in Food Science \& Technology, vol. 114, no. 8, pp. 722-737, 2021.

[10] D. Yu and Z. Zou, "Empirical research on the interaction between marine scientific and technological innovation and marine economic development," Journal of Coastal Research, vol. 108 , no. 1 , pp. $1-8,2020$

[11] P. Galeazzi and A. Galeazzi, "The ecological rationality of decision criteria," Synthese, vol. 198, no. 6, Article ID 11241, 2020.

[12] S. Budiyanti, H. M. Siahaan, and K. Nugroho, "Social communication relation of Madurese people in Max Weber rationality perspective," Jurnal Studi Komunikasi (Indonesian Journal of Communications Studies), vol. 4, no. 2, p. 389, 2020.

[13] T. W. Hung, "Nonhuman rationality: a predictive coding perspective," Cognitive Processing, vol. 279, no. 1, pp. 353-362, 2021.

[14] J. Zhang and N. University, "Analyzing conflict talk from the rationality perspective," Modern Foreign Languages, vol. 42, no. 01, pp. 25-36, 2019.

[15] B. Chen, Y. Zou, and L. I. Zhi, "The development history and prospect forecast of characteristic towns from the perspective of planning rationality," Journal of Landscape Research, vol. 11, no. 3, pp. 41-44, 2019.

[16] Q. Shao, H. C. Man, and J. Huang, "Multimedia crowdsourcing with bounded rationality: a cognitive hierarchy perspective," IEEE Journal on Selected Areas in Communications, vol. 37, no. 7, pp. 1478-1488, 2019.

[17] X. Jia and F. Gao, "Exploration of decision-making mechanism of national science and technology tasks under governance framework," Science and Technology Management Research, vol. 40, no. 08, pp. 35-39, 2020.

[18] D. Vagiona and G. Pozoukidou, "Preface to the topical collection on the 16th international conference on environmental science and technology," Euro-Mediterranean Journal for Environmental Integration, vol. 6, no. 1, pp. 1-2, 2021.

[19] M. Z. Allam, "Underlining the role of data science and technology in supporting supply chains, political stability and health networks during pandemics - ScienceDirect," Surveying the Covid-19 Pandemic and its Implications, no. 7, pp. 129-139, 2020.

[20] C. Zheng, C. Lixian, L. Chunhong, and M. Guangyuan, "Thoughts on science and technology service in agricultural research institutes: taking institute of plant protection of hebei academy of agricultural and forestry sciences as an example," Asian Agricultural Research, vol. 12, no. 10, pp. 23-26, 2020.

[21] R. Hirst, "Writing, in English, for publication in science and technology, and policy: the example of nuclear security," Journal of Technical Writing and Communication, vol. 50, no. 1, Article ID 004728161986515, 2020.

[22] K. Katagiri, "Report on 27th AIRAPT international conference on high pressure science and technology," The Review of High Pressure Science and Technology, vol. 30, no. 1, pp. 49-50, 2020.

[23] Y. Wu and Y. Wu, "Research on the influencing factors of collaborative innovation of science and technology in the pearl river delta urban agglomeration," Journal of Physics: Conference Series, vol. 1616, no. 8, Article ID 012036, 2020.

[24] C. J. Obi, Q. Xiong, and M. Y. Appiah, "Indian journal of science and technology Using genetic algorithm to solve multiple traveling salesman problemconsidering Carbon emissions," Indian Journal of Science and Technology, vol. 13, no. 36, pp. 1-9, 2020.

[25] T. Thawarom and W. Singhasiri, "Lexical richness of oneminute speaking task by science and technology university students," Journal of Asia TEFL, vol. 17, no. 1, pp. 70-86, 2020.

[26] M. M. Zheleznov, O. I. Karasev, S. S. Trostyansky, and E. A. Shitov, "Critical technologies in the system of science and technology priorities of the railway industry: global experiences," World of Transport and Transportation, vol. 17, no. 5, pp. 16-37, 2020.

[27] A. Mamhoori, "Science and technology parks of developing countries as a new way for return on talents (RoT) case study: pardis technology park (PTP)," SSRN Electronic Journal, no. 1, pp. 15-20, 2020.

[28] J. C. Orji, C. S. Gana, V. S. Ezema et al., "Assessment of the efficacy of creativity-based instructional model on scientific attitude in basic science and technology among pupils[J]," Global Journal of Health Science, vol. 12, no. 5, pp. 1-10, 2020.

[29] J. T. Pruonosa, J. M. Raya, and R. D. Fernández, "The economic and social value of science and technology parks. The case of tecnocampus," Frontiers in Psychology, vol. 11, no. 1, pp. 1-10, 2020.

[30] M. Asad, R. Muhammad, N. Rasheed, S. D. M. Chethiyar, and A. Ali, "Unveiling antecedents of organizational politics: an exploratory study on science and technology universities of Pakistan," International Journal of Advanced Science and Technology, vol. 26, no. 6, pp. 2057-2066, 2020.

[31] K. E. Supriya and R. K. Rao, "IoT based real time water level monitoring using Texas instruments' CC3200," Indian Journal of Science and Technology, vol. 13, no. 17, pp. 1720-1729, 2020.

[32] L. O. Raji, M. Babashani, G. J. Akorede et al., "Changes in semen, hormonal profile and testicular morphology of west african dwarf goat bucks treated with danazol," Turkish Journal of Agriculture - Food Science and Technology, vol. 8, no. 12, pp. 2570-2573, 2020. 
[33] G. Pak, Y. Noh, M. I. Lee et al., "Korea institute of ocean science and technology earth system model and its simulation characteristics," Ocean Science Journal, vol. 56, no. 1, pp. 87-92, 2021.

[34] L. Y. Qiao and Z. Y. Qiu, "Algorithm for electromagnetic spectrum resource scheduling based on cognitive radio technology," Computer Simulation, vol. 37, no. 10, pp. 407$411,2020$. 